Revta brasil. Bot., São Paulo, V.24, n.2, p.181-193, jun. 2001

\title{
Biologia da polinização e da reprodução de três espécies de Combretum Loefl. (Combretaceae)
}

\author{
ZELMA GLEBYA MACIEL QUIRINO ${ }^{1}$ e ISABEL CRISTINA MACHADO ${ }^{1,2}$
}

(recebido: 1 de março de 2000; aceito: 14 de fevereiro de 2001)

\begin{abstract}
Reproductive biology and pollination of three species of Combretum Loefl. (Combretaceae)). The reproductive biology and pollination of three species of the genus Combretum were studied in natural populations, in areas of Caatinga (C. leprosum Mart. and C. pisonioides Taub.) and Atlantic forest (C. fruticosum (Loefl.) Stuntz) in Pernambuco and Paraíba states, northeastern Brazil. All the species presented continuous flowering after the rainy season. The colors of the flowers change during the anthesis period. Sugar concentration in the nectar is about $20.9 \%(\mathrm{sd}=2.08)$ in C. pisonioides, $21.3 \%(\mathrm{sd}=2.97)$ in C. leprosum and $9.6 \%(\mathrm{sd}=0.86)$ in C. fruticosum. The three species are self-incompatible. Pollen viability is higher than $95 \%$. The flowers of $C$. pisonioides and C. leprosum have mellittophilous attributes. C. pisonioides is pollinated by wasps of the genus Polybia. C. leprosum is pollinated by ca. 20 species of Hymenoptera and Lepidoptera. Apis mellifera (Apidae) was the most frequent visitor to the flowers of this species. C. fruticosum is ornithophilous, pollinated by passerine birds (Coerebidae) and hummingbirds (Chlorostilbon aureoventris).
\end{abstract}

RESUMO - (Biologia da polinização e da reprodução de três espécies de Combretum Loefl. (Combretaceae)). Foram estudadas a biologia floral, a polinização, a reprodução e a fenologia de três espécies de Combretum em populações naturais, ocorrentes em áreas diferentes de Caatinga (C. leprosum Mart. e C. pisonioides Taub.) e de Mata Atlântica (C. fruticosum (Loefl.) Stuntz) em Pernambuco e na Paraíba, Nordeste do Brasil. As três espécies apresentam floração contínua, que se inicia após o período de chuvas. As flores mudam de cor, durante o período de antese. A concentração média de açúcares no néctar é de $20,9 \%(\mathrm{sd}=2,08)$ em Combretum pisonioides, $21,3 \%(\mathrm{sd}=2,97)$ em C. leprosum e 9,6\% (sd = 0,86) em C. fruticosum. As três espécies são auto-incompatíveis, com viabilidade polínica superior a $95 \%$. Combretum pisonioides e C. leprosum apresentam características melitófilas, sendo a primeira polinizada por vespas do gênero Polybia. Foram observadas cerca de 20 espécies diferentes de visitantes em flores de Combretum leprosum, entre Himenópteros e Lepidópteros, sendo Apis mellifera (Apidae) a mais freqüente. Combretum fruticosum é ornitófila, sendo polinizada por pássaros nectarívoros (Coerebidae) e beija-flores (Chlorostilbon aureoventris).

Key words - Combretum, pollination, mellittophily, ornithophily, caatinga, Atlantic forest

\section{Introdução}

O gênero Combretum encontra-se distribuído na Ásia, África e nas Américas (Exell 1931, Stace 1980) com cerca de 200 espécies, com hábito arbóreo, arbustivo ou lianas e inflorescências em espigas, racemos ou panículas (Barroso et al. 1984).

As espécies de Combretum são polinizadas por pequenos insetos, sendo algumas polinizadas por beija-flores (Gentry 1991), aves e/ou primatas (Prance 1980, Janson et al. 1981). Diferenças adaptativas como forma, tamanho e cor das flores indicam um grande espectro de biótipos florais no gênero.

A maioria dos estudos sobre biologia da polinização de Combretum enfoca apenas a espécie C. fruticosum (Loefl.) Stuntz, em diferentes populações na Costa Rica (Schemske 1980), no

1. Universidade Federal de Pernambuco, CCB, Departamento de Botânica, 50372-970 Recife, PE, Brasil.

2. Autor para correspondência: imachado@npd.ufpe.br
México (Gryj et al. 1990) e na Argentina (Bernadello et al. 1994), observando-se divergência entre os autores com relação aos polinizadores efetivos, se beija-flores e/ou outras aves.

No presente trabalho são apresentadas informações sobre a biologia floral de três espécies de Combretum, ocorrentes em vegetação de caatinga (C. pisonioides Taub., C. leprosum Mart.) e em Mata Atlântica (C. fruticosum), no Nordeste do Brasil, descrevendo, comparativamente, a biologia floral e o sistema de reprodução destas três espécies.

\section{Material e métodos}

Locais de estudo - As observações de campo foram realizadas no período de agosto de 1996 a outubro de 1997, em três diferentes localidades: na Fazenda Maniçoba, Município de Taperoá, Estado da Paraíba (6 $6^{\circ} 6^{\prime}$ S e $36^{\circ} 40^{\prime}$ W) para C. leprosum Mart.; na Fazenda Serrote, Município de Alagoinha $8^{\circ} 27^{\prime} \mathrm{S}$ e $36^{\circ} 46^{\prime} \mathrm{W}$, para C. pisonioides Taub. e na Reserva Ecológica de Tapacurá, Município de São Lourenço da Mata $7^{\circ} 59^{\prime} \mathrm{S}$ e $35^{\circ} 2^{\prime} \mathrm{W}$, para $C$. fruticosum (Loefl.) Stuntz, estas duas últimas localidades no Estado de Pernambuco.

A Fazenda Maniçoba apresenta vegetação do tipo caatinga arbustiva aberta, com muitas espécies caducifólias 
(Andrade-Lima 1981). O clima é semi-árido quente (Bsh), com chuvas de verão (segundo classificação de Köppen) e temperatura média anual de $30{ }^{\circ} \mathrm{C}$ (Governo do Estado da Paraíba/SE/UFPB 1985). As chuvas são irregulares, sendo a precipitação anual de 250 a $600 \mathrm{~mm}$, podendo a estação seca durar cerca de 10 meses do ano (Núcleo de Meteorologia Aplicada 1987). Foram estudados dois agrupamentos, distantes entre si $400 \mathrm{~m}$, cada um com cerca de 30 indivíduos.

A Fazenda Serrote, localizada na região Agreste do Estado de Pernambuco, também apresenta vegetação de Caatinga, constituída de vegetação xerófila, arbustiva e arbórea, sendo tipicamente decídua (Sampaio 1995). O clima é do tipo muito quente, semi-árido (BSs'h'), segundo classificação de Köppen, com temperatura média de $23,5^{\circ} \mathrm{C}$. A população estudada era constituída de 16 indivíduos.

A terceira localidade, Reserva Ecológica de Tapacurá, está situada na zona da mata de Pernambuco, representando um ponto de ligação das florestas orientais brasileiras que vêm do Sul, com as florestas equatoriais vindas da Amazônia (Andrade-Lima 1963). Apresenta vegetação de mata seca, predominantemente arbórea, atingindo cerca de $30 \mathrm{~m}$ de altura, com um estrato intermediário bastante denso, constituído por espécies escandentes. Apresenta elevado grau de pluviosidade, podendo atingir cerca de $2.300 \mathrm{~mm}$ anuais (Andrade-Lima 1970). As observações de campo foram realizadas em três indivíduos. Biologia floral e visitantes - Foram registrados dados sobre morfologia das flores, horário, sequiência e duração da antese, locais de produção e classificação de odores, bem como volume e concentração de néctar. As medidas de concentração e volume de néctar foram feitas em intervalos regulares de duas horas, durante todo o período de produção de néctar. A concentração foi medida com refratômetro de bolso e o volume de néctar com auxílio de microseringas. A receptividade do estigma foi testada com peróxido de hidrogênio (Zeisler 1938). A viabilidade polínica foi verificada através da coloração do citoplasma com carmim acético 2\% (Radford et al. 1974), sendo utilizadas cinco flores de 10 inflorescências, de diferentes indivíduos para as três espécies. A contagem dos grãos de pólen nas três espécies foi realizada utilizando-se câmara de Newbauer, sendo os botões previamente fixados em ácido lático e glicerina 3:1 (Lloyd 1972). A razão pólen/óvulo das três espécies foi determinada de acordo com Cruden (1977).

Para o estudo da fenologia reprodutiva, indivíduos das três espécies foram monitorados durante o período de floração.

Foram feitos testes de polinização manual (Radford et al. 1974) para análise do sistema reprodutivo. Para estimar a produção de frutos em condições naturais (controle), botões foram marcados e observados até a senescência floral ou desenvolvimento dos frutos. Para estimar a eficiência do polinizador, botões foram emasculados na fase de pré-antese, marcados e não ensacados. A eficácia reprodutiva (sensu Ruiz \& Arroyo 1978) foi estimada através da razão entre os resultados obtidos para o controle e os tratamentos de polinização cruzada manual (xenogamia).

$\mathrm{O}$ comportamento dos visitantes às flores foi estudado diretamente no campo, sendo complementado pela análise de fotografias. Foram registrados aspectos referentes ao horário, frequiência (número de visitas), duração e comportamento de visita, bem como local de contacto com pólen e estigma. Exsicatas das três espécies de Combretum foram depositadas no Herbário do Departamento de Botânica da Universidade Federal de Pernambuco (UFP 20248, 20249, 20250).

\section{Resultados}

Características das espécies - Combretum pisonioides Taub. é um arbusto, com alguns indivíduos atingindo cerca de $3 \mathrm{~m}$. As flores estão dispostas em racemos axilares e/ou terminais, com hipanto formado pelo cálice tubuloso e estilete e estames exsertos. O número de botões por inflorescência, diâmetro das flores e número de peças florais encontram-se na tabela 1 . Os oito filetes estão cobertos por tricomas na região de fusão dos mesmos com a porção superior do hipanto. O estilete é simples e o ovário adnato ao hipanto, com cinco óvulos. As anteras bitecas são dorsifixas com deiscência rimosa, sendo o pólen amarelo, com viabilidade de $95 \%$ (tabela 1 ).

Combretum leprosum Mart. possui hábito arbustivo escandente, com 2-3 m de altura, caracterizado pela presença de ramos longos, geralmente volúveis. As flores estão dispostas em panículas, podendo o eixo principal da inflorescência atingir mais de $1 \mathrm{~m}$ de comprimento e comportar 20-45 flores, abrindo-se 5-10 flores por dia (tabela 1). O cálice também é tubuloso e os estames ocupam a mesma posição da espécie anteriormente descrita. $\mathrm{O}$ estilete é simples e o ovário adnato ao hipanto, com cinco óvulos. Oito filetes estão inseridos na região superior do hipanto. O pólen é amarelo, com viabilidade de 97,7\% (tabela $1)$.

Combretum fruticosum (Loefl.) Stuntz é uma liana que habita preferencialmente ambientes úmidos, possui ramos cilíndricos e estriados e inflorescências com flores terminais e/ou axilares. $\mathrm{O}$ número de flores/inflorescência é indicado na tabela 1. A abertura das flores se dá de maneira semelhante às espécies anteriores. $\mathrm{O}$ cálice é tubuloso com estames e estigma exsertos e as flores são do tipo pincel (sensu Faegri \& Van der Pijl 1979), dispostas em densas espigas. $\mathrm{O}$ ovário localiza-se na base do hipanto e contém seis óvulos. Os oito estames estão inseridos na região mediana do hipanto, recoberta por tricomas. As anteras são bitecas, dorsifixas, com deiscência rimosa. As anteras e os grãos de pólen são 
Tabela 1. Número de botões por inflorescência, média das medidas das flores e peças florais, viabilidade polínica e razão pólen/óvulo nas três espécies de Combretum estudadas.

\begin{tabular}{lccc}
\hline Caracteres & C. pisonioides & C. leprosum & C. fruticosum \\
\hline Botões/ inflorescência $(\mathrm{N}=30)$ & $8-12(\overline{\mathrm{x}}=9)$ & $20-45(\overline{\mathrm{x}}=35)$ & $42-90(\overline{\mathrm{x}}=70)$ \\
Diâmetro floral $^{2}(\mathrm{~mm})$ & 2,5 & 3 & 4 \\
Comprimento $(\mathrm{mm})^{1}$ & $5-8(\overline{\mathrm{x}}=6)$ & $9-10(\overline{\mathrm{x}}=9)$ & $22-25(\overline{\mathrm{x}}=25)$ \\
Floral $^{1}$ & 3,5 & 6,2 & 14 \\
Hipanto & 2,0 & 1,0 & 1,5 \\
Pétala & 3,7 & 6 & 22 \\
Estilete & 4,0 & 5 & 14 \\
Filete & 7.680 & 3.360 & 7.200 \\
Razão pólen/óvulo & 95 & 97,7 & 98 \\
Viabilidade polínica $(\% \mathrm{x})$ & $(93-97)$ & $(95,6-99)$ & $(96-99,8)$ \\
(Faixa de variação) & & & \\
\hline
\end{tabular}

1. da base do ovário até a extremidade do estilete.

2. os diâmetros florais foram calculados na região de inserção das pétalas.

vermelhos, sendo a viabilidade polínica de $98 \%$ (tabela 1).

Antese - Em C. pisonioides, a abertura das flores inicia-se às 6:00 h, com a distensão do estigma, que já se encontra receptivo, tendo esta fase de distensão a duração de aproximadamente um dia (tabela 2, estádio I). A fase seguinte caracteriza-se pela distensão dos estames, sendo o pólen liberado logo em seguida (tabela 2, estádios II e III). Após a abertura completa da flor, as anteras situam-se em posição acima do estigma (figura 1). Diariamente abrem-se de duas a quatro flores em cada inflorescência, sendo inicialmente as flores da região central da inflorescência e a seguir as marginais. Não foi percebido odor nas flores. No primeiro dia de antese, as flores possuem coloração branca, permanecendo assim até o quarto ou quinto dia, quando mudam para vermelho, coloração que perdura por mais quatro dias, iniciando-se em seguida o processo de murcha.

As flores de C. leprosum iniciam sua abertura por volta das 5:00 h, com o aparecimento do estigma e o gradual crescimento do estilete (figura 2). A seguir ocorre a distensão dos estames, um de cada vez. Este processo de abertura gradual da flor chega a perdurar toda a manhã do primeiro dia de antese (tabela 2, estádios I e II). A coloração inicial das flores é branca, mudando gradualmente a partir do segundo dia, para amarelo. O estigma já se encontra receptivo desde o início do processo, permanecendo assim até a mudança de coloração das flores, que ocorre a partir do segundo dia. A deiscência das anteras ocorre cerca de duas horas após a distensão dos estames, sendo o pólen liberado nos dois primeiros dias. Desde o início do processo de abertura, as flores exalam odor adocicado, principalmente nas pétalas e estames. As flores permanecem abertas e vistosas por mais dois ou três dias até murcharem e começarem a cair (tabela 2, estádios III e IV).

O processo de antese em C. fruticosum ocorre de forma semelhante ao das outras duas espécies, iniciando às 6:00 h, com a distensão do estigma (figura 3). A seguir, ocorre a distensão dos estames e a deiscência das anteras, sendo o pólen liberado nos dois primeiros dias (tabela 2, estádios I e II). O processo de antese se encerra entre o quinto e sexto dia, quando as flores murcham e caem (tabela 2, estádios III e IV). Nenhum odor foi percebido nas estruturas florais. A coloração inicial das flores é verde, ocorrendo uma mudança para laranja no segundo dia, tornando-se vermelhas a partir do quarto dia, durando esta fase ainda, mais um ou dois dias (tabela 2).

As características florais e as mudanças verificadas ao longo do processo de antese das três espécies, encontram-se resumidas na tabela 2 e figuras 1-3. 
Tabela 2. Características das flores das três espécies de Combretum estudadas e as mudanças ocorrentes durante o processo de antese (- ausente; + presente).

\begin{tabular}{|c|c|c|c|c|}
\hline Estádios & Características & C. pisonioides & C. leprosum & C. fruticosum \\
\hline \multirow[t]{8}{*}{ Estádio I } & Cor Corola & branca & branca & verde \\
\hline & Cálice & branco & verde & verde \\
\hline & Estigma & receptivo & receptivo & receptivo \\
\hline & Anteras & fechadas & deiscentes & deiscentes \\
\hline & Néctar & - & + & + \\
\hline & Visitas & - & freqüentes & freqüentes \\
\hline & Odor & - & + & - \\
\hline & Duração & $1 \mathrm{dia}$ & 1 dia & 1 dia \\
\hline \multirow[t]{8}{*}{ Estádio II } & Cor Corola & branca & amarela & laranja \\
\hline & Cálice & verde & verde & alaranjado \\
\hline & Estigma & receptivo & não receptivo & não receptivo \\
\hline & Anteras & deiscentes & deiscentes & deiscentes \\
\hline & Néctar & + & - & - \\
\hline & Visitas & freqüentes & raras & raras \\
\hline & Odor & - & + & - \\
\hline & Duração & 3-4 dias & 2 dias & 1 dia \\
\hline \multirow[t]{8}{*}{ Estádio III } & Cor Corola & avermelhada & amarela & vermelho-alaranjada \\
\hline & Cálice & verde & verde-amarelado & laranja-avermelhado \\
\hline & Estigma & não receptivo & não receptivo & não receptivo \\
\hline & Anteras & vazias & vazias & vazias \\
\hline & Néctar & - & - & - \\
\hline & Visitas & raras & - & - \\
\hline & Odor & - & + & - \\
\hline & Duração & 1 dia & $1 \mathrm{dia}$ & 2 dias \\
\hline \multirow[t]{8}{*}{ Estádio IV } & Cor Corola & vermelha & amarela & vermelha \\
\hline & Cálice & avermelhado & amarelo & vermelho \\
\hline & Estigma & não receptivo & não receptivo & não receptivo \\
\hline & Anteras & vazias & vazias & vazias \\
\hline & Néctar & - & - & - \\
\hline & Visitas & - & - & - \\
\hline & Odor & - & - & - \\
\hline & Duração & 3-4 dias & $1-2$ dias & $1-2$ dias \\
\hline Duração Total & & 8-10 dias & $4-5$ dias & 5 dias \\
\hline
\end{tabular}

O néctar é armazenado na região do hipanto, abaixo da inserção dos filetes, estando sua produção limitada a um único dia, nas três espécies estudadas (tabela 2). Em C. pisonioides e C. leprosum, a produção de néctar diminui durante o dia cessando no período da tarde, enquanto a concentração aumenta, chegando ao seu pico no final da tarde (figuras 4A; B). A concentração de néctar em $C$. fruticosum, permanece relativamente estável, com uma pequena elevação no período entre meio-dia e 14:00 h. O volume também decresce ao longo do dia, como ocorreu nas duas espécies anteriores (figura $4 C)$.

A concentração média de açúcares no néctar foi de $21 \%$ ( $\pm 2,08)$ em Combretum pisonioides, $21 \%$ $( \pm 2,97)$ em $C$. leprosum e $9 \%( \pm 0,86)$ em $C$. fruticosum.

Fenologia - O período de floração e de frutificação das três espécies estudadas está esquematizado na figura 5. As três espécies florescem na estação chuvosa (janeiro a setembro), sendo que $C$. fruticosum floresce no final da estação chuvosa. 


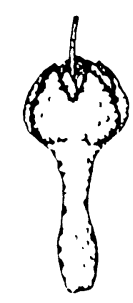

I

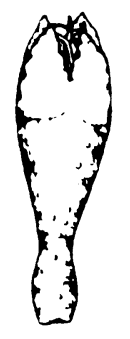

I

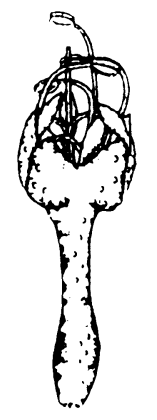

II

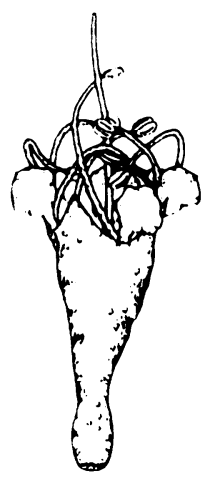

I - II

I - II

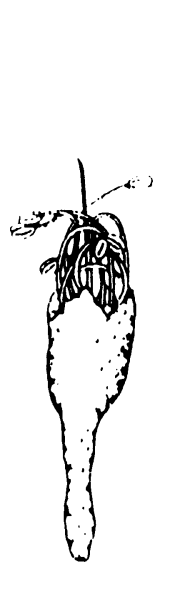

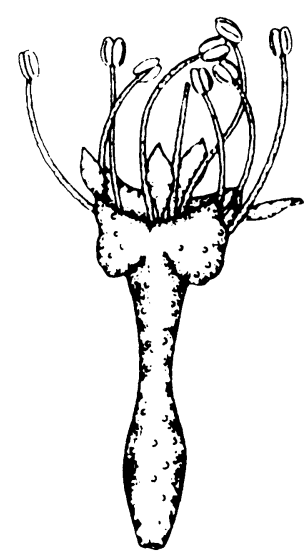

II, III - IV

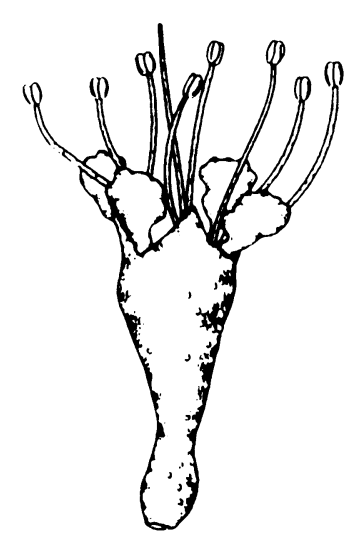

II, III - IV

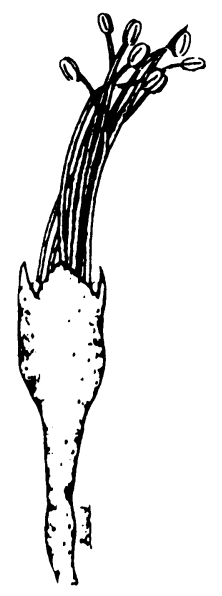

II, III - IV

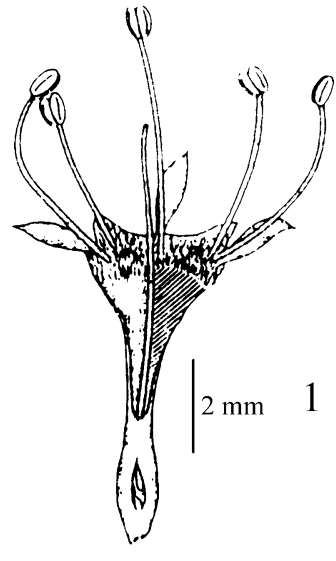

V

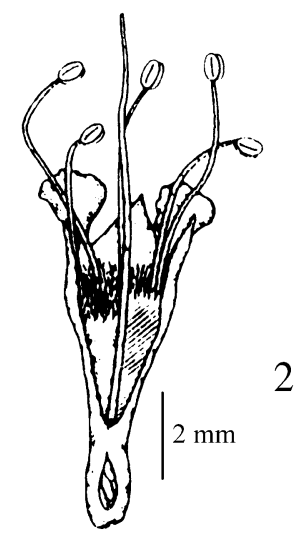

V

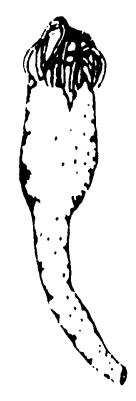

I

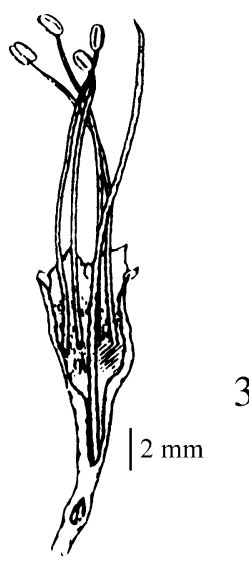

$\mathrm{V}$

Figuras 1-3. Estádios de antese (I, II, III, IV), correspondendo aos períodos caracterizados na tabela 3, e corte longitudinal (V) das flores das três espécies de Combretum. 1. C. pisonioides; 2. C. leprosum; 3. C. fruticosum. A região hachurada representa o local de secreção de néctar. 

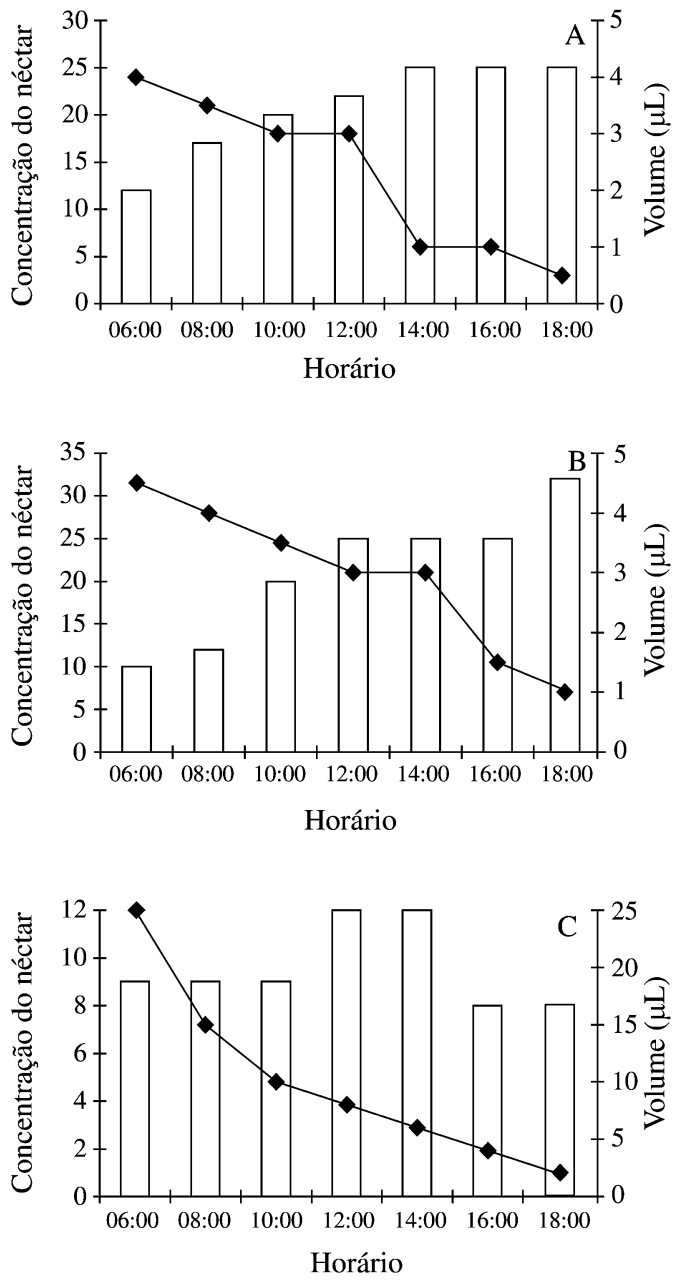

Figura 4. Concentração e volume de néctar ao longo do dia nas três espécies de Combretum estudadas. A. C. pisonioides; B. C. leprosum; C. C. fruticosum. ( $\square$ ) concentração; ( $\bullet$ volume.

Sistema Reprodutivo - Os experimentos para a verificação do sistema reprodutivo nas três espécies de Combretum, bem como a quantidade de frutos formados em condições naturais, estão sumarizados na tabela 3. Os testes para verificação da taxa de fecundação cruzada em $C$. fruticosum não foram realizados, uma vez que o baixo número de indivíduos, não proporcionaria um resultado estatisticamente confiável. Os resultados indicam que as espécies são autoincompatíveis e não apomíticas.

Visitantes - Os visitantes às flores das três espécies de Combretum estão relacionados na tabela 4.
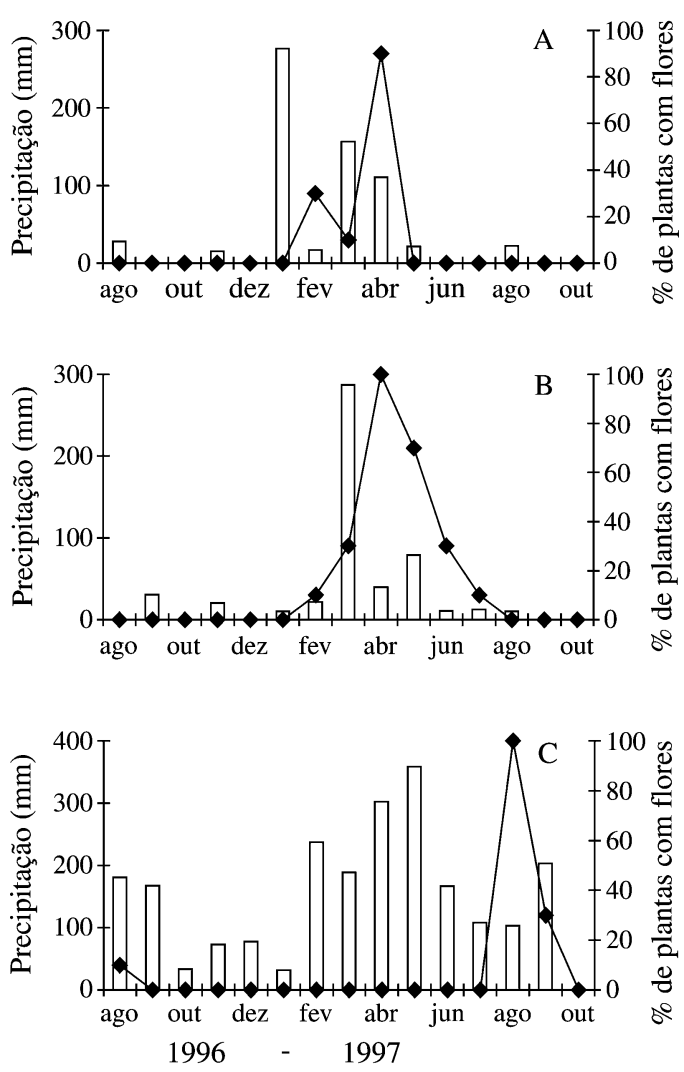

Figura 5. Período de floração, percentual de plantas com flores das três espécies de Combretum e precipitação pluviométrica do local no respectivo período. A. C. pisonioides; B. C. leprosum; C. C. fruticosum. ( $\square$ ) precipitação $(\mathrm{mm}) ;(\diamond) \%$ de plantas em floração.

Combretum pisonioides - As primeiras visitas iniciaram-se às 7:00 $\mathrm{h}$ com três espécies de vespas do gênero Polybia, sendo estes os visitantes mais frequientes (tabela 4). A maioria das flores visitadas tinha cor branca, ou seja, flores do segundo ao terceiro dia. As visitas no período da tarde eram esporádicas, sendo a última visita registrada às 16:00 h do quarto dia, não sendo observados visitantes noturnos.

Polybia scutellaris foi a espécie mais freqüente, tendo sido responsável por $70 \%$ do total de visitas. Esta vespa inicialmente sobrevoava a planta e pousava em uma flor, apoiando-se com as pernas nas demais flores da inflorescência, introduzindo em seguida o aparelho bucal na flor, para a retirada do néctar. Neste momento, a parte ventral de seu abdômen, a região intercoxal e/ou a cabeça 
Tabela 3. Resultado dos experimentos sobre o sistema reprodutivo de Combretum pisonioides, C. leprosum e C. fruticosum, da formação de frutos em condições naturais, da eficiência do polinizador e da eficácia reprodutiva. Em C. fruticossum, não foram realizadas polinizações cruzadas.

\begin{tabular}{lccc}
\hline Tratamento & C. pisonioides & C. leprosum & C. fruticosum \\
\hline $\begin{array}{l}\text { Apomixia } \\
\text { Autopolinização }\end{array}$ & $0(30 / 0)^{1}$ & $0(50 / 0)$ & $0(20 / 0)$ \\
$\quad$ & & & \\
$\quad$ espontânea & $0(50 / 0)$ & $0(50 / 0)$ & $0(50 / 0)$ \\
$\quad$ manual & $0(50 / 0)$ & $0(50 / 0)$ & $0(30 / 0)$ \\
Geitonogamia & $0(50 / 0)$ & $0(50 / 0)$ & $0(50 / 0)$ \\
$\begin{array}{l}\text { Xenogamia } \\
\text { Eficiência do } \\
\text { polinizador }\end{array}$ & $20(50 / 10)$ & $16(50 / 8)$ & - \\
$\begin{array}{l}\text { Controle } \\
\text { Eficácia }\end{array}$ & $10(50 / 8)$ & $12(50 / 6)$ & $10(50 / 5)$ \\
reprodutiva & 0,5 & $19(100 / 19)$ & $8(50 / 4)$ \\
\hline
\end{tabular}

1. percentual dos frutos formados (número de flores/número de frutos).

2. flores emasculadas e não ensacadas. contactavam as anteras e o estigma. O tempo de permanência na inflorescência era de 60 segundos, sendo visitadas cerca de cinco flores por inflorescência e cinco inflorescências por planta, a cada visita. Durante o estudo, foi observado que esta espécie, em algumas visitas no período da tarde, agarrava-se às anteras com suas pernas, coletando pólen. O comportamento das outras espécies de vespas, menos freqüentes, foi semelhante ao de Polybia scutellaris, apesar da diferença de tamanho entre elas.

Uma espécie da família Sphecidae realizou, durante todo o trabalho de campo, apenas quatro visitas às flores de $C$. pisonioides, coletando néctar e contactando o estigma, durante o início do período de floração. Ocasionalmente, moscas das famílias Tachinidae, Syrphidae e Sarcophagidae, em um total de cinco espécies, foram observadas coletando néctar.

Tabela 4. Visitantes das flores das três espécies de Combretum, com respectivas freqüência de visitas e eficiência na polinização. $\mathrm{F}=$ Freqüentes $(\geq 35 \%) ; \mathrm{P}=$ Pouco freqüentes (16 a 35\%); $\mathrm{R}=$ Raras (6 a 15\%); $\mathrm{M}=$ Muito raras (até 5\%); 1 = eficiente; 2 = ocasional; $3=$ pilhador.

\begin{tabular}{|c|c|c|c|}
\hline Visitantes & C. pisonioides & C. leprosum & C. fruticosum \\
\hline \multicolumn{4}{|l|}{ AVES } \\
\hline \multicolumn{4}{|l|}{ Coerebidae } \\
\hline Coereba flaveola $\mathrm{L}$. & - & - & $\mathrm{F} / 1$ \\
\hline \multicolumn{4}{|l|}{ Thraupidae } \\
\hline Cyanerpes cyaneus $\mathrm{L}$. & - & - & $\mathrm{P} / 2$ \\
\hline \multicolumn{4}{|l|}{ Trochilidae } \\
\hline Chlorostilbon aureoventris (d'Orbigny \& Lafresnaye, 1838) & - & - & $\mathrm{F} / 1$ \\
\hline \multicolumn{4}{|l|}{ INSETOS } \\
\hline \multicolumn{4}{|l|}{ Hymenoptera } \\
\hline \multicolumn{4}{|l|}{ Apidae } \\
\hline Apis mellifera (L., 1758) & $\mathrm{M} / 3$ & $\mathrm{~F} / 1$ & - \\
\hline Trigona spinipes (Fabricius, 1793) & $\mathrm{R} / 3$ & $\mathrm{R} / 2$ & $\mathrm{R} / 2$ \\
\hline \multicolumn{4}{|l|}{ Halictidae } \\
\hline Auglochloropsis sp. & - & $\mathrm{M} / 3$ & - \\
\hline \multicolumn{4}{|l|}{ Pompilidae } \\
\hline sp. 1 , sp. 2 & - & $\mathrm{P} / 3$ & - \\
\hline \multicolumn{4}{|l|}{ Vespidae } \\
\hline Mischocyttarus sp. & - & - & $\mathrm{M} / 3$ \\
\hline Polistes canadensis $(\mathrm{L} ., 1758)$ & - & $\mathrm{R} / 2$ & $\mathrm{~F} / 3$ \\
\hline Polybia ignobilis (Haliday, 1836) & $\mathrm{P} / 1$ & - & - \\
\hline Polybia jurinei (Saussure, 1854) & - & - & $\mathrm{R} / 3$ \\
\hline Polybia paulista (Ihering, 1896) & $\mathrm{R} / 1$ & - & - \\
\hline
\end{tabular}


(cont.)

\begin{tabular}{|c|c|c|c|}
\hline Visitantes & C. pisonioides & C. leprosum & C. fruticosum \\
\hline Polybia scutellaris (White, 1841) & $\mathrm{F} / 1$ & - & - \\
\hline Protonectarina sylveirae (Saussure, 1854) & $\mathrm{R} / 1$ & - & - \\
\hline Synoeca surinama $(\mathrm{L} ., 1759)$ & - & - & $\mathrm{F} / 3$ \\
\hline $\begin{array}{l}\text { Sphecidae } \\
\text { sp. } 1\end{array}$ & $\mathrm{R} / 2$ & - & - \\
\hline $\begin{array}{l}\text { Sarcophagidae } \\
\quad \text { Boettcheria sp. } \\
\text { sp.1 }\end{array}$ & $\begin{array}{c}M / 3 \\
-\end{array}$ & - & $\overline{\mathrm{M} / 3}$ \\
\hline $\begin{array}{l}\text { Stratiomyidae } \\
\quad \text { sp. } 1 \\
\text { sp. } 2\end{array}$ & $\begin{array}{l}- \\
-\end{array}$ & $\begin{array}{c}M / 3 \\
-\end{array}$ & $\overline{\mathrm{M} / 3}$ \\
\hline $\begin{array}{l}\text { Syrphidae } \\
\text { Anidia } \mathrm{sp} . \\
\text { Volucella } \text { sp. }\end{array}$ & $\begin{array}{l}\mathrm{R} / 3 \\
\mathrm{R} / 3\end{array}$ & - & - \\
\hline $\begin{array}{l}\text { Tachinidae } \\
\text { sp. } 1, \text { sp. } 2\end{array}$ & $\mathrm{M} / 3$ & - & - \\
\hline $\begin{array}{l}\text { Lepidoptera } \\
\text { Hesperiidae }\end{array}$ & & & \\
\hline $\begin{array}{l}\text { Urbanus simplicius L., } 1763 \\
\text { Urbanus } \mathrm{sp} . \\
\text { Pyrgus } \mathrm{sp} . \\
\text { Eneides isabella dianosa (Hübner, 1806) }\end{array}$ & $\begin{array}{l}- \\
- \\
-\end{array}$ & $\begin{array}{l}\mathrm{R} / 2 \\
\mathrm{R} / 2 \\
\mathrm{R} / 3 \\
-\end{array}$ & $\begin{array}{l}- \\
- \\
- \\
R / 3\end{array}$ \\
\hline $\begin{array}{l}\text { Pyrrhoyginae } \\
\text { sp. } 1\end{array}$ & - & $\mathrm{R} / 3$ & - \\
\hline $\begin{array}{l}\text { Nymphalidae } \\
\text { Agraulis vanillae maculosa (Stichel., 1907) } \\
\text { Anartia jatrophae (L., 1763) } \\
\text { Dryas iulia (Cr., 1779) } \\
\text { Junonia evarete (Cr., 1779) } \\
\text { Yphthimoides sp. }\end{array}$ & $\begin{array}{l}- \\
- \\
- \\
-\end{array}$ & $\begin{array}{l}\mathrm{P} / 2 \\
\mathrm{R} / 2 \\
\mathrm{R} / 2 \\
\mathrm{P} / 1 \\
-\end{array}$ & $\begin{array}{l}- \\
- \\
- \\
- \\
P / 2\end{array}$ \\
\hline $\begin{array}{l}\text { Papilionidae } \\
\text { Battus polydamas }(\mathrm{L} ., 1758) \\
\text { Anosia gilippus }(\mathrm{Cr} ., 1775)\end{array}$ & - & $\begin{array}{l}\mathrm{P} / 2 \\
\mathrm{M} / 2\end{array}$ & - \\
\hline $\begin{array}{l}\text { Pieridae } \\
\quad \text { Asaia sp. } \\
\text { sp.1 }\end{array}$ & $\begin{array}{l}- \\
-\end{array}$ & $\mathrm{R} / 2$ & $\begin{array}{c}- \\
\mathrm{R} / 2\end{array}$ \\
\hline $\begin{array}{l}\text { Noctuidae } \\
\quad \text { sp.1, sp.2, sp.3, sp.4 }\end{array}$ & - & $\mathrm{M} / 3$ & - \\
\hline $\begin{array}{l}\text { Pyralidae } \\
\text { sp. } 1 \text {, sp. } 2 \text {, sp. } 3 \text {, sp. } 4 \text {, sp. } 5 \text {, sp. } 6\end{array}$ & - & $\mathrm{M} / 3$ & - \\
\hline
\end{tabular}

Combretum leprosum - Um grande número de insetos foi observado nas flores de $C$. leprosum, tendo sido registradas cerca de 29 espécies, entre abelhas, borboletas, mariposas e vespas (tabela 4). As primeiras visitas se iniciaram às 6:00 $\mathrm{h}$ e as últimas às 18:00 h, sendo o período da manhã o de maior frequiência de visitantes (figura 6).

Dentre os insetos, a abelha Apis mellifera (Apidae) foi a espécie mais freqüente, sendo responsável por cerca de $50 \%$ do total de visitas. As 


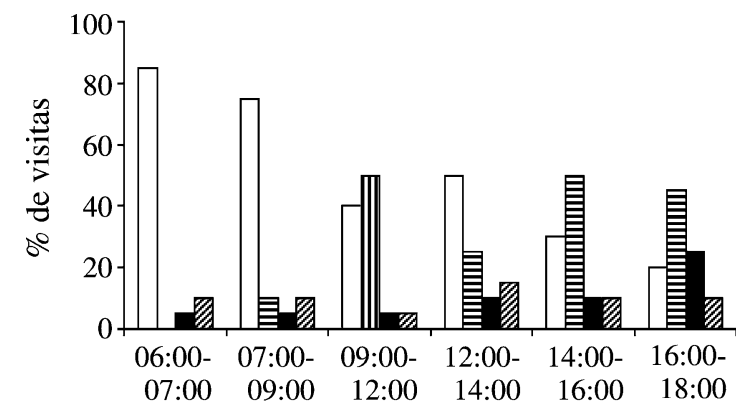

Horário

Figura 6. Freqüência dos visitantes em Combretum leprosum. ( $\square$ ) Apis mellifera; (目) borboletas; ( $\square$ ) mariposas; ( $\square$ ) outros.

abelhas inicialmente aproximavam-se da planta e pousavam nas flores brancas, onde coletavam néctar e pólen. A aproximação às flores era frontal, agarrando-se em seguida à parede do hipanto e aos estames. Ao tomar o néctar, introduzindo o aparelho bucal no interior do hipanto, contactavam as anteras e estigma, ficando o pólen aderido à parte ventral do abdômen e à região intercoxal. A visita a cada flor durava cerca de 5-10 segundos, porém a permanência da abelha em uma dada inflorescência variava de acordo com o número de flores brancas disponíveis.

A borboleta Junonia evarete, responsável por cerca de $25 \%$ das visitas, foi o segundo visitante mais freqüente. As visitas iniciavam-se às 9:00 h estendendo-se até às 15:00 h. No período do meio-dia o número de visitas era reduzido. Ao introduzir a probóscide no tubo da corola para tomar o néctar, a borboleta permanecia com suas asas abertas, contactando as estruturas reprodutivas da flor com as asas, a parte ventral do tórax e do abdômen.

O comportamento de Anartia jatrophae, Dryas iulia, Agraulis vanillae maculosa e Anosia gilippus foi semelhante ao da espécie anteriormente descrita, porém as visitas eram mais esporádicas.

Três espécies de Hesperiidae visitaram as flores durante todo o dia, coletando néctar e geralmente não contactando com o estigma, sendo apenas pilhadores. As espécies Urbanus simplicius e Urbanus sp. possuem comportamento de polinizadores eventuais. Estes insetos eram facilmente afastados pelas abelhas, porém em populações de $C$. leprosum, onde a freqüência de Apis era menor, observou-se que uma espécie da subfamília Pyerhopyginae estava presente em grande quantidade, chegando a ser o visitante exclusivo em algumas plantas.

Combretum fruticosum - Três espécies de aves foram observadas visitando as flores de C. fruticosum, correspondendo a cerca de $70 \%$ do total das visitas. Os demais visitantes observados foram borboletas, vespas e abelhas (tabela 4). As visitas das aves iniciavam-se às 6:00 h, prolongando-se até às 17:00 h (figura 7).

O beija-flor Chlorostilbon aureoventris (Trochilidae), responsável por $60 \%$ do total de visitas realizadas por aves, foi observado durante todo o dia. No início e pico da floração, durante o período da manhã, comportava-se como territorialista. Ao término de cada visita, deslocava-se para outra inflorescência ou pousava em galhos próximos sem afastar-se da planta, reiniciando posteriormente as visitas. No período da tarde, o comportamento mudava para linha de captura ("trap-lining"), com visitas em intervalos regulares, de 30-40 minutos, sendo o local abandonado em seguida. Ao final da floração, foram observadas apenas visitas esporádicas no período da manhã. Durante as visitas, o animal pairava defronte a uma inflorescência e introduzia o bico no interior do hipanto da flor, para retirada de néctar, momento em que contactava as anteras, ficando o pólen aderido, tanto na parte superior como na inferior do bico, devido à disposição central dos elementos sexuais da flor. As visitas em cada flor duravam cerca de 2 segundos, sendo visitadas apenas as flores de coloração verde.

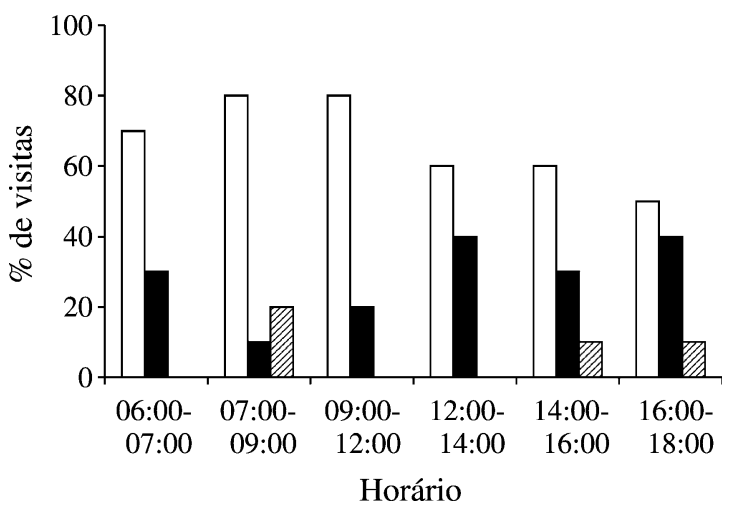

Figura 7. Frequiência de visitas das espécies de aves em Combretum fruticosum; ( $\square$ ) Chlorostilbon aureoventris; Coereba flaveola; (囚) Cianerpes cyaneus. 
Duas outras espécies de aves foram observadas, sendo Coereba flaveola (Coerebidae) responsável por cerca de $35 \%$ das visitas. Este pássaro pousava agarrando-se ao eixo da inflorescência e introduzia o bico na corola coletando néctar em flores de cor verde, contactando, neste momento, as anteras e o estigma da flor. Estas aves forrageavam geralmente em bando, procurando inflorescências mais altas, menos visitadas por beija-flores. As visitas ocorreram com maior frequiência durante o período da manhã, entre 6:00 e 9:00 h, tendo sido registradas poucas visitas à tarde.

Cyanerpes cyaneus (Thraupidae), com comportamento semelhante à espécie anterior, foi responsável por $5 \%$ das visitas, a maioria no período da manhã. Borboletas Yphthimoides sp. e Eneides isabella dianosa foram pouco frequientes nas flores de $C$. fruticosum, sendo suas visitas ilegítimas, pois não ocorria o contato com o estigma.

Polistes canadensis e Synoeca surinama (Vespidae) foram observadas freqüentemente roubando néctar de flores de $C$. fruticosum através de um orifício feito no cálice, por suas mandíbulas, na região do tecido nectarífero. Inflorescências inteiras eram danificadas, não sendo posteriormente visitadas por aves. Outras duas espécies de vespas, duas de Sarcophagidae e uma de Stratiomyidae utilizaram, posteriormente, o mesmo orifício para roubar o néctar.

Trigona spinipes foi a única espécie de visitante comum às três de Combretum estudadas, coletando pólen no período da manhã, locomovendo-se sobre as anteras e eventualmente contactando o estigma.

\section{Discussão}

Flores - As três espécies de Combretum estudadas apresentam flores com diferentes atributos associados à atração dos polinizadores. Em Combretum pisonioides e C. leprosum, características florais como antese diurna, corolas relativamente curtas, cor branca, baixa produção de néctar e muitas flores por inflorescência, são atributos considerados por Faegri \& Van der Pijl (1979) como associados à síndrome da melitofilia. A emissão de odor adocicado em C. leprosum é outro caráter melitófilo.
As flores de C. fruticosum divergem em algumas características das espécies anteriores, como tamanho, coloração, produção e concentração de néctar. A disposição ereta das flores de $C$. fruticosum, além do fato de serem do tipo pincel e apresentarem forma tubulosa, associada à ausência de odor, permitem enquadrar esta espécie na síndrome de ornitofilia (Faegri \& Van der Pijl 1979, Stiles 1981). Embora a maioria das flores visitadas tenha a coloração verde, a cor vermelha das anteras, dos grãos de pólen, bem como das flores e inflorescências em estágio final, funcionam como atrativo visual para aves (Faegri \& Van der Pijl 1979).

A permanência das flores, mesmo após o período de produção de néctar, nas três espécies de Combretum estudadas, parece aumentar o potencial atrativo para os visitantes. Por outro lado, a mudança de coloração das flores nas três espécies e a concomitante interrupção na produção de néctar podem funcionar como um alerta aos visitantes da presença ou não de recompensa. Relação semelhante foi observada por Eisikowitch \& Rotem (1987) em Quisqualis indica (Combretaceae), na qual as flores mudavam de coloração ao mesmo tempo em que cessava a produção de néctar.

O aumento na concentração de néctar ao longo do dia em Combretum pisonioides e C. leprosum pode estar relacionado a mudanças de temperatura (Baker \& Baker 1983) e umidade relativa (Corbet et al. 1979), considerando o ambiente onde se encontram. Alterações na concentração de néctar, ao longo do dia, em espécies de caatinga também foram observadas em Ruellia asperula, Acanthaceae (Machado \& Sazima 1995).

A produção de néctar por apenas um dia como encontrado em flores de $C$. fruticosum foi semelhante ao observado para esta mesma espécie por Schemske (1980). A concentração de néctar observada para $C$. fruticosum, se mantém relativamente constante, situação semelhante ao de uma população estudada na Argentina (Bernadello et al. 1994), e contrastante com outros estudos para a espécie (Baker 1975, Arizmendi \& Ornelas 1990 e Gryj et al. 1990).

O período de floração das espécies de Combretum está diretamente relacionado com a estação chuvosa. Combretum pisonioides e $C$. 
leprosum, espécies ocorrentes em regiões áridas, possuem floração do tipo cornucópia (sensu Gentry 1974). De acordo com a classificação de Newstron et al. (1994), o padrão de floração nessas duas espécies é anual. A interrupção no período de floração em $C$. pisonioides foi um reflexo da ausência de chuvas neste mesmo período na região (cf. figura 5A).

Combretum fruticosum apresenta muitas flores abertas por dia em curto espaço de tempo. Este padrão corresponde, em alguns aspectos (número de flores/dia, período de duração das flores), ao padrão de espécies com floração anual descrito por Newstron et al. (1994). Um período de floração curto pode ser uma tendência encontrada em lianas polinizadas por beija-flores (Stiles 1978).

Combretum pisonioides, $C$. leprosum e $C$. fruticosum são espécies alógamas. Embora não tenham sido realizados experimentos de polinização cruzada em C. fruticosum a ausência de fomação de frutos nos testes de autogamia e geitonogamia, associados à baixa taxa de formação natural de frutos (cf. tabela 3), indicam a presença de um sistema de reprodução xenogâmico. Bernadello et al. (1994) obtiveram resultados semelhantes para esta espécie. Da mesma maneira, os resultados obtidos por Schemske (1980) para C. farinosum evidenciaram a presença de alogamia. Estes resultados sugerem que a autoincompatibilidade pode ser o sistema de reprodução predominante no gênero Combretum. A elevada razão $\mathrm{P} / \mathrm{O}$ encontrada para as espécies estudadas neste trabalho corresponde aos valores estabelecidos por Cruden (1977) para espécies xenogâmicas. A razão $\mathrm{P} / \mathrm{O}$ não parece ser influenciada pelo ambiente, pois as espécies ocorrentes em regiões de caatinga (C. pisonioides $\mathrm{e}$ C. leprosum) apresentaram valores muito diferentes, estando a razão $\mathrm{P} / \mathrm{O}$ de $C$. pisonioides mais próxima de $C$. fruticosum, a qual encontra-se em ambiente de mata.

Os resultados da eficácia reprodutiva nas espécies $C$. pisonioides e $C$. leprosum, foram diferentes. O baixo sucesso reprodutivo de $C$. pisonioides pode estar relacionado ao baixo número de visitas ou pouca eficiência do polinizador, uma vez que os valores obtidos nos testes de polinização cruzada manual apresentaram resultados superiores. Em Combretum leprosum, embora exista uma grande variedade de visitantes, os polinizadores são mais eficientes, resultando numa eficácia reprodutiva alta.

Visitantes - Dentre os visitantes observados em $C$. pisonioides, as vespas do gênero Polybia foram os polinizadores efetivos, embora seja bastante discutido o papel de vespas como polinizadores (Faegri \& Van der Pijl 1979), uma vez que, em geral, restringem-se apenas a pilhar o néctar. Heithaus (1979) menciona que vespas preferem espécies de flores brancas, com corolas curtas e dispostas em inflorescências congestas. Geralmente, estas espécies são também visitadas por um grande número de insetos. Em $C$. pisonioides as visitas de outros insetos ocorreram em proporções muito baixas, caracterizando as vespas como polinizadores efetivos.

Embora a maioria dos estudos relatem a utilização apenas de néctar pelas vespas, para consumo próprio, foi observada a coleta do pólen de C. pisonioides por Polybia scutellaris. A coleta de pólen e a possível polinização de Asclepiadaceae por vespas do gênero Polybia, também foi constatada por Höfling \& Machado (1985), tendo sido observado pólen nas pernas e nos ninhos das vespas durante o inverno, possivelmente para a alimentação de suas larvas. Considerando o comportamento alimentar do gênero Polybia observado nestes estudos, pode-se sugerir uma relação entre vespas deste gênero e a polinização de algumas espécies de plantas de famílias tropicais.

As flores de Combretum leprosum são visitadas por diferentes espécies de insetos, podendo ser consideradas como inseto-generalistas (sensu Gentry 1991). Embora Apis mellifera tenha sido o polinizador mais efetivo, este não deve ser o primário pois, além desta abelha ser uma espécie introduzida, em outras populações de C. leprosum esta espécie não foi registrada. Quatro espécies de borboletas polinizaram as flores de C. leprosum, porém suas eficiências dependem da freqüência de suas visitas, as quais são limitadas por interações agressivas com Apis. Embora a eficiência da psicofilia seja discutível em plantas de regiões tropicais (Machado \& Sazima 1987), a grande proporção de visitas de borboletas em C. leprosum pode significar uma possível psicofilia nesta espécie. 
Os demais visitantes são considerados como polinizadores eventuais ou pilhadores.

Assim como neste estudo, observações anteriores feitas em C. fruticosum fora do Brasil, também evidenciaram visitas por beija-flores e outras aves nectarívoras (Alvarez del Toro 1963, Schemske 1980, Gryj et al. 1990, Trombulak 1990 e Bernadello et al. 1994). Embora muitas flores polinizadas por beija-flores estejam reunidas em inflorescências (Grant \& Grant 1968), sua arquitetura é diferente das inflorescências com flores polinizadas por aves que pousam, as quais, em sua maioria, possuem flores na posição horizontal (Westerkamp 1990, Sazima et al. 1993, Endress 1994). As inflorescências de C. fruticosum atendem às características para ambos os tipos de polinizadores.

Alguns estudos em outras populações sugerem que os polinizadores efetivos de Combretum fruticosum sejam beija-flores (Schemske 1980). Por sua vez, Gryj et al. (1990) sugerem que os polinizadores efetivos sejam pássaros nectarívoros. Em seus estudos, Bernadello et al. (1994) afirmam que a polinização é realizada por ambos, pássaros nectarívoros e beija-flores. Neste estudo, ambos também atuaram como polinizadores, embora o comportamento territorialista dos beija-flores não contribua para o sucesso reprodutivo, devido às repetidas visitas à mesma planta numa espécie auto-incompatível. Alternativamente, a redução do volume de néctar contornaria este problema (Stiles 1975). No caso de C. fruticosum, a mudança de comportamento apresentada pelo beija-flor (de territorialista para linha de captura ("trap-lining") durante o dia, parece ser influenciada pela quantidade de néctar disponível, favorecendo assim a polinização cruzada. A ausência do comportamento territorialista também ao final da floração pode estar relacionada à quantidade de néctar disponível (Trombulak 1990).

Os pássaros da espécie Cyanerpes cyaneus também apresentaram comportamento territorialista, impedindo que outras aves nectarívoras coletassem néctar em $C$. fruticosum. A freqüência das visitas destas aves, porém, não é afetada pelos beija-flores, uma vez que as inflorescências visitadas por estas aves, em geral, não são as mesmas.
Embora a eficiência de cada grupo de polinizador (pássaros nectarívoros e beija-flores) possa estar relacionada com a frequiência das visitas (Bernadello et al. 1994), a indicação do polinizador mais eficiente de $C$. fruticosum depende também do comportamento de visita. Neste estudo, apesar dos beija-flores deterem a maior freqüência de visitas, a espécie Coereba flaveola foi considerada o polinizador mais eficiente.

Agradecimentos - A Carlos Gomes, Sérgio Maciel e Eduardo Gonçalves dos Santos, pelo auxílio no trabalho de campo. Aos Professores Clemens Schlindwein e Maria Regina de Vasconcelos Barbosa, pelas sugestões ao manuscrito. Aos Professores Celso F. Martins, Fátima Silva e Edilberto Granolti, pela identificação das abelhas, borboletas e vespas. A Maria Iracema Bezerra e Ariadna Valentina Lopes, pelo auxílio na bibliografia consultada. A esta última também pelas sugestões ao texto. A Luciana Teixeira e Mary Janice Santos, pelo auxílio no trabalho de laboratório. À UFRPE, pela permissão para estudo de campo na Reserva Ecológica de Tapacurá. Ao CNPq, pelo apoio financeiro.

\section{Referências bibliográficas}

ALVAREZ DEL TORO, M. 1963. La enredadera cepillo, fuente de atracción para les aves. Miscelánea Ornitológica 10:3-11.

ANDRADE-LIMA, D. 1963. A fitogeografia do Brasil: características, problemas e perspectivas. Revista Brasileira de Geografia 25:493-496.

ANDRADE-LIMA, D. 1970. Recursos vegetais de Pernambuco. Boletim Técnico. Recife. 41: 1-32.

ANDRADE-LIMA, D. 1981. O domínio da caatinga. Revista Brasileira de Botânica 4:149-163.

ARIZMENDI, M.C. \& ORNELAS, J.F. 1990. Hummingbirds and their floral resources in tropical dry forest in Mexico. Biotropica 22:172-180.

BAKER, H.G. 1975. Sugar concentration in nectars from hummingbird flowers. Biotropica 7:37-41.

BAKER, H.G. \& BAKER, I. 1983. Floral nectar sugar constituents in relation to pollination type. In Handbook of experimental pollination biology (C.E. Jones \& R.J. Little, eds.). Van Nostrand Reinhold, New York, p.117-141.

BARROSO, G.M., GUIMARÃES, E.F., ICHASO, C.L.F., COSTA, C.G. \& PEIXOTO, A.L. 1984. Sistemática de Angiospermas do Brasil. v. 2. Imprensa Universitária, Viçosa.

BERNADELLO, L., GALETTO, L. \& RODRIGUEZ, I.G. 1994. Reproductive biology, variability of nectar features and pollination of Combretum fruticosum (Combretaceae), in Argentina. Botanical Journal of Linnean Society 114:293-308.

CORBET, S.A., UNWIN, D.M. \& PRYS-JONES, O.E. 1979. Humidity, nectar and insects visits to flowers, with special reference to Crataegus, Tilia and Echium. Ecological Entomology 4:9-22. 
CRUDEN, R.W. 1977. Pollen-ovule ratios: a conservative indicative of breeding systems in flowering plants. Evolution 31:32-46.

EISIKOWITCH, D. \& ROTEM, R. 1987. Flower orientation and color change in Quisqualis indica and their possible role in pollinator partitioning. Botanical Gazette 148:175-179.

ENDRESS, P.K. 1994. Diversity and evolutionary biology of tropical flowers. Pergamon Press, London.

EXELL, A.W. 1931. The genera of Combretaceae. Journal of Botany 69:113-128.

FAEGRI, K. \& VAN DER PIJL, L. 1979. The principles of pollination ecology. Pergamon Press, London.

GENTRY, A.H. 1974. Flowering phenology and diversity in tropical Bignoniaceae. Biotropica 6:64-68.

GENTRY, A.H. 1991. Breeding and dispersal systems of lianas. In The Biology of vines. (F.E. Putz \& H.A. Mooney, eds.). Cambridge University Press, Cambridge, p.393-423.

GOVERNO DO ESTADO DA PARAÍBA/ SECRETARIA DE EDUCAÇÃO/ UNIVERSIDADE FEDERAL DA PARAÍBA. 1985. Atlas geográfico do Estado da Paraíba. Grafset. João Pessoa.

GRANT, K. \& GRANT, V. 1968. Hummingbird and their flowers. Columbia University Press, New York.

GRYJ, E., MARTÍNEZ DEL RIO, C. \& BAKER, I. 1990. Avian pollination and nectar use in Combretum fruticosum (Loefl.) Stuntz. Biotropica 22:266-271.

HEITHAUS, E.R. 1979. Community structure of neotropical flower visiting bees and wasps: diversity and phenology. Ecology 60:190-202.

HÖFLING, J.C. \& MACHADO, V.L.L. 1985. Análise populacional de colônias de Polybia ignobilis (Haliday, 1836) (Hymenoptera, Vespidae). Revista Brasileira de Entomologia 29:271-284.

JANSON, C.H., TERBORGH, J. \& EMMONS, L.H. 1981. Non flying mammals as pollinating agents in the Amazonian forest. Biotropica 13:1-6.

LLOYD, D.G. 1972. Breeding systems in Cotula L. (Compositae, Anthemideae). I. The array of monoclinous and diclinuos systems. New Phytologist 71:1118-1119.

MACHADO, I.C.S. \& SAZIMA, M. 1987. Estudo comparativo da biologia floral de duas espécies invasoras: Ipomoea hederifolia e I. quamoclit (Convolvulaceae). Revista Brasileira de Biologia 47:425-436.

MACHADO, I.C.S. \& SAZIMA, M. 1995. Biologia da polinização e pilhagem por beija-flores em Ruellia asperula Lindau (Acanthaceae) na caatinga, nordeste brasileiro. Revista Brasileira de Botânica 18:24-33.
NEWSTRON, L.E., FRANKIE, G.W. \& BAKER, H.G. 1994. A new classification for phenology based on flowering patterns in Lowland Tropical Rain Forest trees at La Selva, Costa Rica. Biotropica 26:141-159.

NÚCLEO DE METEREOLOGIA APLICADA. 1987. Atlas geográfico do Estado da Paraíba. 2 ed. Universidade Federal da Paraíba, Campina Grande.

PRANCE, G.T. 1980. A note on the probable pollination of Combretum by Cebus. Biotropica 12:239.

RADFORD, A.E., DICKINSON, W.C., MASSEY, J.R. \& BELL, C.R. 1974. Vascular plant systematics. Harper \& Row Publishers, New York.

RUIZ, T.Z. \& ARROYO, M.T.K. 1978. Plant reproductive ecology of a secondary deciduous tropical forest in Venezuela. Biotropica 10:221-230.

SAMPAIO, E.V.S.B. 1995. Overview of the Brazilian caatinga. In Seasonally dry tropical forests (S.H. Bullock, H.A. Mooney \& E. Medina, eds.). Cambridge University Press, Cambridge, p.35-63.

SAZIMA, I., BUZATO, S. \& SAZIMA, M. 1993. The bizarre inflorescence of Norantea brasiliensis (Marcgraviaceae): visits of hovering and perching birds. Botanica Acta 106:507-513.

SCHEMSKE, D.W. 1980. Floral ecology and hummingbird pollination of Combretum farinosum in Costa Rica. Biotropica 12:169-181.

STACE, C.A. 1980. The significance of the leaf epidermis in taxonomy of the Combretaceae: conclusions. Botanical Journal of the Linnean Society 81:327-339.

STILES, F.G. 1975. Ecology, flowering phenology, and hummingbird pollination of some Costa Rica Heliconia species. Ecology 56:285-301.

STILES, F.G. 1978. Temporal organization of flowering among the hummingbird foodplants of a tropical wet forest. Biotropica 10:194-210.

STILES, F.G. 1981. Geographical aspects of bird-flower coevolution with particular reference to Central America. Annals of the Missouri Botanical Garden 68:323-351.

TROMBULAK, S.C. 1990. Assesment of territory value by tropical hummningbird (Amazilia saucerottei). Biotropica 22:9-15.

WESTERKAMP, C. 1990. Bird-flowers, hovering versus perching exploitation. Botanica Acta 103:366-371.

ZEISLER, M. 1938. Über die Abgrenzung der eigentlichen Narberfläche mit Hilfe von Reaktionen. Beihefte zum Botanischer Zentralblatt 58:308. 